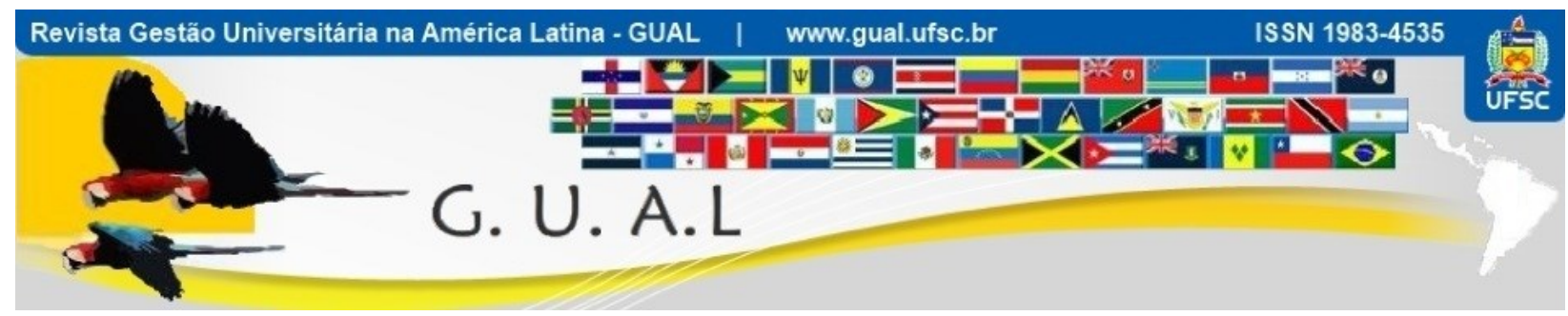

DOI: http://dx.doi.org/10.5007/1983-4535.2018v11n2p249

\title{
OS FATORES DE ENGAJAMENTO DO ESTUDANTE NA MODALIDADE DE ENSINO A DISTÂNCIA
}

\section{STUDENT ENGAGEMENT FACTORS ON DISTANCE LEARNING}

Letícia Martins de Martins, Doutora Instituto Federal do Rio Grande do Sul - IFRS leticia.martins@rolante.ifrs.edu.br

José Luis Duarte Ribeiro, Doutor Universidade Federal do Rio Grande do Sul - UFRGS ribeiro@producao.ufrgs.br

Recebido em 21/outubro/2016

Aprovado em 22/fevereiro/2018

Sistema de Avaliação: Double Blind Review 


\title{
RESUMO
}

O engajamento dos estudantes é uma medida de qualidade institucional. Quanto mais engajados os estudantes estiverem em atividades educacionais, melhor é a instituição (KUH; HU, 2001). Excelência em educação superior ocorre em universidades que maximizem boas práticas que incentivam engajamento acadêmico e social (PASCARELLA, 2001). Para Chen, Gonyea e Kuh (2008), um tema ainda não estudado diz respeito à qualidade das experiências de aprendizagem em cursos a distância e o nível de envolvimento nas atividades dos cursos. Neste sentido, este artigo apresenta e discute os fatores de engajamento dos estudantes do EAD. O estudo foi realizado através de uma pesquisa qualitativa, apoiada na condução de grupos focados. Para tanto, foi inicialmente realizada uma revisão da literatura existente buscando levantar os fatores de engajamento dos estudantes da modalidade a distância. Após a realização deste levantamento foram conduzidos quatro grupos focados a fim de realizar uma análise do conjunto de fatores e identificar aqueles que geram engajamento acadêmico especificamente no ensino à distância. A análise permitiu o levantamento de 60 fatores geradores do engajamento de estudantes da modalidade de ensino a distância, subdivididos em 11 dimensões.

Palavras-chave: Engajamento do Estudante. Ensino a Distância. Avaliação da Educação Superior.

\begin{abstract}
The student engagement is an institutional quality measure. As students are more engaged in educational activities, better is the institution (KUH, HU, 2001). Excellence in higher education takes place in universities that maximize good practices that encourage academic and social engagement (PASCARELLA, 2001). A topic not studied yet regards to the quality of learning experiences in distance courses and the level of engagement in the activities of these courses (CHEN; GONYEA; KUH, 2008). This article presents and discusses the engagement factors of distance education students. The study was conducted through a qualitative research, supported in conducting focus groups. It was initially carried out a review of the existing literature in order to raise the engagement factors of students in distance learning. The analysis identifies 60 factors of student engagement in distance learning, divided into 11 dimensions.
\end{abstract}

Keywords: Student Engagement . Distance Learning. Evaluation of Higher Education. 


\section{INTRODUÇÃO}

Nos últimos anos, tem-se observado um crescimento no número de cursos de ensino superior. Em particular, a modalidade de ensino a distância (EAD), tanto no Brasil quanto no exterior, tem possibilitado o acesso ao ensino superiora um número crescente de estudantes. Apesar de não ser uma prática recente, apenas em 1996, com a edição da Lei de Diretrizes e Bases (Lei 9.394/96), essa modalidade de ensino foi regulamentada no Brasil. Apoiado nessa regulamentação, desde o ano 1999, o Ministério da Educação tem credenciado Instituições de Ensino Superior (IES) permitindo EAD tanto em nível de graduação como de pós-graduação. A partir de então, observa-se a proliferação de instituições ofertando EAD e a implantação de polos dessa modalidade em todo país. Atualmente, existem em torno de 1.000.000 de estudantes matriculados em mais de 400 Instituições de Ensino Superior credenciadas para oferta de EAD em todo o Brasil (INEP, 2013).

O EAD, regulamentado pelo Decreto 2.494, de 10/02/1998, conceitua esta modalidade como "uma forma de ensino que possibilita a autoaprendizagem, com a mediação de recursos didáticos sistematicamente organizados apresentados em diferentes suportes de informação, utilizados isoladamente ou combinados, e veiculados pelos diversos meios de comunicação" (MEC, 2010). Essa modalidade de ensino tem sua identidade própria. A essa identidade são caracterizados diferentes atributos desde a sua concepção, em seus projetos de curso, até sua implantação. O EAD modifica a relação tradicional entre discente e docente. O conceito de autoridade do professor e seu domínio sobre o processo de ensino transformam-se em compartilhamento do aprendizado. Surge uma nova interface entre alunos e professores, mediada pelas tecnologias da informação e comunicação (TICs). Existe a presença dos tutores desempenhando mais o papel de facilitadores do que de especialistas, tendo em vista que os cursos serão menos estruturados e mais adaptados à realidade do discente, sendo atribuída aos próprios alunos a responsabilidade de sua aprendizagem. Esses conceitos reforçam a ideia de que os alunos aprenderão por fazer e não por memorizar (MAIA; MEIRELLES, 2003). Portanto, se os estudantes são responsáveis pela sua própria aprendizagem, pode-se afirmar que a garantia da qualidade do ensino dependerá em grande escala do engajamento do discente ao longo de seu curso de graduação.

Os primeiros estudos sobre engajamento demonstravam que os estudantes obtêm maiores ganhos quando eles devotam mais tempo e energia para certas atividades que requerem mais esforço que outras, tais como estudando, interagindo com colegas ou 
professores discutindo temas relevantes, aplicando sua aprendizagem em situações concretas em tarefas de diferentes contextos e assim por diante (PACE, 1990). As atuais pesquisas sugerem que os estudantes de diferentes origens em geral se beneficiam com as práticas de engajamento, apesar dos efeitos serem diversos, significando que alguns estudantes se beneficiam mais do que outros em certas atividades (PASCARELLA; TERENZINI, 2005). O engajamento tem efeito sobre as notas e persistência do acadêmico, principalmente quando eles são envolvidos desde o primeiro ano (CRUCE et al., 2006; KUH et al., 2008; PASCARELLA; TERENZINI, 2005). Estar engajado também influencia positivamente a aprendizagem continuada após a finalização do curso superior (CHEN; GONYEA; KUH, 2008). Pesquisadores da área confirmaram ainda que o engajamento do estudante tem um impacto positivo no desempenho acadêmico e na satisfação do estudante com relação às experiências ao longo da vida acadêmica (ASTIN, 1984; TINTO, 1993; PASCARELLA; TERENZINI, 2005).

Pesquisas sobre o tema apontam que o engajamento do estudante está diretamente relacionado com resultados como incremento da aprendizagem e permanência no ensino superior (PASCARELLA; TERENZINI, 2005). O quê as instituições fazem para engajar os estudantes, por vezes denominado valor agregado (ZHAO; KUH, 2004), pode ser pensado como qualidade do ensino. Utilizar o engajamento do estudante como um indicador de qualidade mobiliza uma questão chave: será que as instituições estão aplicando adequadamente seus recursos e considerando as condições prévias do estudante para efetivamente conduzir o mesmo ao aprendizado (KUH et al. 2009) e possibilitar ingresso no mercado de trabalho (HU; WOLNIAK, 2010)? Um problema de pesquisa que merece investigação seria identificar a melhor maneira de incorporar o processo de engajamento do estudante em avaliações de qualidade (EWELL; JONES, 1996; PASCARELLA, 2001).

Se por um lado existe a questão da qualidade da oferta do ensino, por outro, o número crescente de Instituições credenciadas nos últimos anos no Brasil vem trazendo outra preocupação, a concorrência. As Instituições de Ensino Superior, ao longo dos últimos anos, estão concorrendo umas com as outras na busca de novos alunos e manutenção de seus estudantes. As políticas e práticas adotadas pelas Instituições de ensino influenciam o nível de engajamento e a permanência dos estudantes no campus (PIKE; KUH, 2005). Ao invés de analisar quais os recursos disponíveis para os estudantes, deve-se avaliar o que os estudantes fazem e quanto se envolvem com os recursos disponíveis (ROBINSON; HULLINGER, 2008). 
Neste sentido, este artigo apresenta e discute os fatores de engajamento dos estudantes do EAD. O estudo foi realizado através de uma pesquisa qualitativa, apoiada na condução de grupos focados.

Este artigo está estruturado em cinco seções. Após esta introdução, são apresentados os conceitos relacionados ao engajamento no EAD. Na seção seguinte, é apresentado o método de pesquisa, incluindo os detalhes da coleta de dados. A seguir são apresentados os resultados dos grupos focados, que conduziram a identificação dos fatores de engajamento no EAD. Por fim, são traçadas as considerações finais

\section{ENGAJAMENTO NO ENSINO A DISTÂNCIA}

Apesar do EAD não ser um fenômeno novo, seu desenvolvimento e adoção por meio de sofisticadas tecnologias da comunicação vem sendo aprimorado nos últimos anos de forma notável. O uso de computadores e tecnologias móveis tem proporcionado novas alternativas de acesso ao conhecimento. Porém, a ênfase não pode ser dada somente aos aspectos tecnológicos, sob pena de prejudicar sua principal função: o processo de ensino aprendizagem (SHERRY, 1995). O conceito fundamental da educação a distância está relacionado a tempo e espaço, no qual professores e estudantes encontram-se em distintos locais a maior parte do tempo em que acontece o processo de ensino-aprendizagem. No que diz respeito ao tempo, dependendo da estrutura do curso, o aluno escolherá o melhor momento para ter suas aulas. Neste sentido, professores e estudantes necessitarão de algum tipo de ferramenta para que ocorra a interação entre ambos. A tecnologia atrelada ao conhecimento vem permitindo a oferta de cursos de educação superior a distância, promovendo aprendizagem do aluno a qualquer hora e lugar.

Atualmente, observa-se um número maior de instituições de ensino superior ofertando cursos na modalidade a distância. Porém, se por um lado crescem a oferta e a demanda desta modalidade de ensino, a preocupação com a qualidade e efetividade é questionada com maior frequência. Pesquisadores da área tendem a focar seus estudos na perspectiva de avaliar se a efetividade da aprendizagem do EAD consegue alcançar os mesmos resultados de aprendizagem se comparados aos do ensino presencial. Os estudos sobre a efetividade do EAD acabam por abranger três distintas categorias, quais sejam: (i) resultados dos estudantes, comparando suas notas; (ii) atitudes dos estudantes no que se refere a aprendizagem; e, (iii) satisfação dos estudantes em relação ao EAD (ROBINSON; HULLINGER, 2008). Grande parte dessas pesquisas aponta que não há diferença significativa entre os resultados de 
aprendizagem dos estudantes das modalidades presenciais e a distância (PALLOFF; PRATT, 2001). No Brasil, no entanto, tomando-se por base o Exame Nacional de Cursos, pode-se afirmar que os alunos da modalidade a distância vêm superando os resultados dos alunos da modalidade presencial (INEP, 2013).

O desenvolvimento da educação a distância não é apenas um fato, mas um mar de mudanças (MAEROFF, 2003). Essas mudanças tem sido uma preocupação contínua em uma série de pesquisas que buscam responder ao questionamento de qual o impacto do uso intensivo de tecnologias baseadas na web em cursos online no engajamento do estudante e em seus resultados de aprendizagem (KUH; HU, 2001; ROBINSON; HULLINGER, 2008).

Ainda verificam-se receios em relação a qualidade do ensino ofertado em cursos da modalidade a distância. Existem evidências de pesquisa afirmando que alguns cursos feitos a distância são impessoais, superficiais, sem foco definido e "desumanizado". Por outro lado, outras pesquisas apontam que cursos a distância bem estruturados poderão alcançar altos índices de satisfação dos alunos, aprendizagem e desenvolver, mesmo que a distância, sentimentos de pertencer a uma comunidade (ROVAI, 2003). Moore et al. (1989) afirmam que ensinar e estudar em cursos a distância podem ter tanta qualidade quanto cursos presenciais se: (i) os métodos e tecnologias aplicadas utilizadas forem apropriados para as tarefas solicitadas; (ii) existam ferramentas que permitam e estimulem a interação entre estudantes; (iii) o feedback dos docentes seja feito em tempo adequado.

É evidente que a avaliação do conhecimento e da aprendizagem dos estudantes é fundamental para todos os envolvidos, governos, instituições de ensino, docentes, estudante e mercado de trabalho, todavia, a avaliação do EAD deve ir além dessas medidas, considerando a qualidade das experiências como um todo. Medidas como o engajamento do estudante podem oferecer insumos para essa avaliação (ROBINSON; HULLINGER, 2008).

\subsection{FATORES DO ENGAJAMENTO NO EAD}

O EAD muda a forma de ensino e o ambiente no qual a aprendizagem ocorre. Assim, é razoável acreditar que também existe uma alteração na forma pela qual o estudante desta modalidade se engaja no seu estudo. A maioria das pesquisas ignora ou dá pouca atenção para o engajamento do estudante no EAD (COATES, 2007). Os estudos sobre engajamento abordam o campus assumindo apenas a sua existência física, ignorando os ambientes virtuais de aprendizagem (AVA). Porém, as novas tecnologias da informação e comunicação (TICs) por si só não conduzem ao sucesso do estudante (CHICKERING; EHRMANN, 1996). 
Quando é dada ênfase demasiada a tecnologia ao invés dos aspectos relacionados ao curso, podem surgir problemas relacionados ao curso e sua condução. Muitos estudos definem as TICs como apenas um dos elementos para promover o engajamento do estudante (KUH; HU, 2001; LAIRD; KUH, 2005; ROBINSON; HULLINGER, 2008). Por exemplo, Robinson e Hullinger (2008), apontaram que tecnologias assíncronas permitem que os estudantes tenham mais tempo para pensar criticamente e refletir. Duderstadt, Atkins, e Houweling (2002) afirmam que os estudantes de cursos a distância têm maior propensão para o trabalho colaborativo, o que é um importante componente para o engajamento do estudante. Os elementos de colaboração são ainda maiores quando incorporados nas plataformas dos cursos a distância (THURMOND; WAMBACH, 2004). Porém, é importante que os administradores de cursos a distância forneçam as instruções suficientes para seus estudantes sobre todos os recursos disponíveis, como biblioteca online, ferramentas de interação, usos dos objetos de aprendizagem, entre outras. As instituições também devem ofertar suporte suficiente para auxiliar nas dificuldades de uso ou técnicas dos sistemas e suas ferramentas (LAPADULA, 2003).

Pesquisas sobre EAD afirmam que: (i) a instrução online pode ser tão efetiva quanto a tradicional presencial; (ii) para que cursos online aconteçam é necessário aprendizagem cooperativa/colaborativa ou aprendizagem ativa; e (iii) presença marcante do instrutor (DIXSON, 2012).

Robinson e Hullinger (2008), tomando por base o instrumento utilizado pelo NSSE, realizaram uma análise em três instituições com oferta de cursos a distância. As dimensões e fatores abordados por esses autores no estudo realizado são apresentados no Quadro 1.

Quadro 1 Fatores utilizados do NSSE para avaliar engajamento de Universidades com oferta de cursos distância

\begin{tabular}{|c|c|c|}
\hline \multicolumn{2}{|c|}{ Dimensões } & Fatores \\
\hline \multirow{3}{*}{$\begin{array}{l}\text { Nível de } \\
\text { desafio } \\
\text { academico }\end{array}$} & $\begin{array}{l}\text { Atividades } \\
\text { mentais }\end{array}$ & $\begin{array}{c}\text { Memorização de fatos, ideias ou métodos; Análise de } \\
\text { ideias, teorias ou experiências; Sintetização e organização } \\
\text { de idéias ou experiências } \\
\text { Julgamento de valor de informações, argumentos ou } \\
\text { métodos }\end{array}$ \\
\hline & $\begin{array}{l}\text { Expectativas e } \\
\text { avaliações }\end{array}$ & $\begin{array}{l}\text { Trabalhar de forma mais intensa do que imaginava que } \\
\text { era capaz }\end{array}$ \\
\hline & $\begin{array}{l}\text { Desenvolvimento } \\
\text { de habilidades }\end{array}$ & $\begin{array}{l}\text { Escrever de forma clara e efetiva; Falar de forma clara e } \\
\text { efetiva; Pensar crítica e analiticamente }\end{array}$ \\
\hline \multicolumn{2}{|c|}{$\begin{array}{l}\text { Interação com os membros do } \\
\text { corpo docente }\end{array}$} & $\begin{array}{l}\text { Discussão de idéias de leituras realizadas ou anotações de } \\
\text { aula; Discussão de provas e trabalhos; Receber feedback } \\
\text { rápido; Discussão de planos para a carreira }\end{array}$ \\
\hline
\end{tabular}




\begin{tabular}{|c|c|c|}
\hline \multicolumn{2}{|c|}{ Aprendizagem ativa e colaborativa } & $\begin{array}{l}\text { Trabalhar com outros estudantes; Realizar trabalhos de } \\
\text { tutoria ou auxiliar outros estudantes; Utilizar a biblioteca } \\
\text { online para encontrar trabalhos já realizados; Realizar } \\
\text { apresentações de aula online; Trabalhar efetivamente com } \\
\text { outros colegas }\end{array}$ \\
\hline \multirow{3}{*}{$\begin{array}{c}\text { Experiências } \\
\text { educacionais } \\
\text { enriquecedoras }\end{array}$} & $\begin{array}{l}\text { Enriquecimento } \\
\text { no uso de TICs }\end{array}$ & $\begin{array}{c}\text { Conhecimento da tecnologia; Uso da tecnologia para } \\
\text { análise de dados; Desenvolvimento de apresentações } \\
\text { online; Uso de computador ou de tecnologia da } \\
\text { informação }\end{array}$ \\
\hline & $\begin{array}{l}\text { Enriquecimento } \\
\text { de vida }\end{array}$ & $\begin{array}{l}\text { Comunicação com outros estudantes sobre assuntos não } \\
\text { relativos à Universidade; Acessar biblioteca online para } \\
\text { assuntos não relativos a trabalhos de aula; Aprender por si } \\
\text { próprio }\end{array}$ \\
\hline & $\begin{array}{l}\text { Enriquecimento } \\
\text { do trabalho }\end{array}$ & $\begin{array}{c}\text { Participar de discussões de aula online; Trabalhar na área } \\
\text { ou realizar trabalhos relativos aos conhecimentos e } \\
\text { habilidades desenvolvidos no curso; Resolver problemas } \\
\text { complexos no mundo real }\end{array}$ \\
\hline
\end{tabular}

Dixson (2012) elaborou sua própria escala para avaliar quais atividades ou canais de interação podem assegurar estudantes mais engajados. Os fatores utilizados por esse autor são descritos no Quadro 2.

Quadro 2 Fatores de engajamento apontados por Dixson, 2012.

\begin{tabular}{|c|c|c|c|}
\hline Habilidades & Emoções & Participação & Desempenho \\
\hline Estudar & Esforçar-se & Acessar o ambiente & Obter boas notas \\
constantemente & Aplicar o que está & várias vezes por & Sair-se bem em testes \\
Fazer todas as tarefas & aprendendo durante o & semana & quizzes \\
de casa & cotidiano & Procurar o instrutor & Ser confiante que é \\
Estar atualizado com & Encontrar maneiras de & com questões sobre os & possível aprender e \\
as leituras & tornar o curso & materiais ou trabalhos & sair-se bem em aula \\
Fazer releituras dos & interessante & Enviar email ou postar & Enviar email para o \\
materiais entre as & Pensar em questões do & questões quando não & instrutor solicitando \\
aulas online para ter & curso continuamente & entender o material ou & informações sobre as \\
certeza que entendeu o & Desejar realmente & o trabalho solicitado & notas \\
conteúdo & aprender & Divertir-se nos chats & Verificar as notas \\
Manter-se organizados & Pensar criticamente & online, discussões ou & online \\
Realizar anotações de & sobre sua própria & via email com os & Avaliar seu próprio \\
leituras, vídeos, etc & ética, prioridades, & colegas ou instrutores & aprendizado e \\
Escutar ou ler com & crenças e valores no & Auxiliar os colegas & progresso. \\
cuidado & contexto de sala de & Participar ativamente & \\
Tirar o máximo de & aula & de pequenos grupos de & \\
vantagem de todos os & & discussão em fóruns & \\
recursos de aula & & Engajar-se em & \\
& & conversas online & \\
& & Postar em discussões & \\
& & de fóruns & \\
& & regularmente & \\
& & Conhecer os colegas & \\
& & &
\end{tabular}


Sun e Rueda (2012) utilizaram em seu modelo de avaliação do engajamento do estudante as variáveis motivacionais e de aprendizagem (interesse, eficácia pessoal e capacidade de organizacional) e seus efeitos sobre o engajamento dos estudantes a distância em sua aprendizagem. Para atingir seu objetivo, os autores utilizaram a conceito de engajamento de Fredricks, Blumenfeld e Paris (2004). Segundo esses autores, o engajamento é composto por componentes comportamental, emocional e cognitivo. Vale destacar que o modelo utilizado por Fredricks, Blumenfeld e Paris foi desenvolvido para alunos de nível médio, e Sun e Rueda o adaptaram para o uso junto a estudantes de nível superior. Para construção do modelo, esses autores também fizeram uso variáveis independentes para descrever as características dos alunos e seus interesses pessoais. Também foi questionada a eficácia no uso do computador e a capacidade de auto organização do aluno.

Chen, Gonyea e Kuh (2008) afirmam que a educação a distância pode ser comparada com a educação presencial, ao menos no que se refere ao engajamento em práticas educacionais. Porém, segundo esses autores, ainda é desconhecido o efeito de atividades típicas de EAD como discussões e trabalhos em grupo onlinee se essas são comparáveis às discussões feitas em sala de aula, incluindo apresentações ou trabalhos em grupo no formato presenciais. Esses autores defendem a necessidade da realização de outras pesquisas no que diz respeito especificamente a questão da aprendizagem ativa e colaborativa na modalidade de EAD.

\section{MÉTODO}

O presente estudo foi realizado por meio de grupos focados, seguindo uma abordagem qualitativa. A condução dos grupos foi feita junto a estudantes da Universidade Federal do Rio Grande do Sul matriculados em curso de graduação na modalidade a distância, bem como estudantes na modalidade presencial durante os meses de maio a junho de 2010. Foram selecionados quatro cursos de diferentes áreas de conhecimento buscando identificar a existência de diferenças nos fatores de engajamentos entre os estudantes. Para coletar os dados foram realizados quatro grupos focados, sendo um grupo para cada curso selecionado. De acordo com Westphal, Bógus e Faria (1996) grupo focado pode ser definido como uma técnica de pesquisa que utiliza sessões na forma de grupos de discussão como fóruns facilitadores da expressão de características psicossociológicas e culturais. Configura uma sessão em grupo na qual os sujeitos do estudo discutem vários aspectos de um tópico 
específico. Krueger e Casey (2000) apontam o número ideal de participantes em um grupo focado "em uma questão não comercial são seis a oito membros". Adicionalmente, Krueger e Casey afirmam que os grupos menores são preferidos para a análise detalhada.

Inicialmente foram realizados grupos focados com alunos pertencentes à modalidade presencial. O objetivo de realizar a primeira coleta com esses alunos era: (i) garantir que as questões a serem aplicadas fossem de fácil compreensão dos respondentes e (ii) obter uma referência a respeito de respostas típicas às questões formuladas. A seleção dos alunos que participaram dos grupos focados presenciais foi por livre adesão. Foram enviados emails para 200 alunos da modalidade presencial convidando os discentes a participarem da discussão. Já em relação aos alunos da modalidade a distância, os coordenadores de cursos forneceram emails a partir da consulta em seus banco de dados. Foi enviado um convite para no mínimo dois alunos de cada polo dos cursos participantes.

Os grupos focados tiveram uma duração média de duas horas conforme sugerido por Ribeiro e Nodari (2009). Os grupos da graduação na modalidade presencial foram realizados no próprio local de ensino. Já os da modalidade a distância foram realizados online, com o apoio de um aplicativo para conversas multi-usuários, tendo em vista a dispersão dos estudantes, bem como a facilidade de manuseio da tecnologia. Os grupos realizados por meio de conversas online foram muito importantes para o levantamento dos fatores. A distribuição do número de participantes e dos cursos selecionados segue nas tabelas a seguir.

Tabela 1 Alunos participantes do grupo focado do curso de pedagogia à distancia

\begin{tabular}{cc}
\hline Polo & Número de alunos de pedagogia \\
\hline TrêsCachoeiras & 2 \\
Alvorada & 2 \\
Sapiranga & 1 \\
Gravataí & 1 \\
São Leopoldo & 2 \\
\hline Total & $\mathbf{8}$ \\
\hline
\end{tabular}

Tabela 2 Alunos participantes do grupo focado do curso de música à distância

\begin{tabular}{cc}
\hline Polo & Número de alunos de Música \\
\hline Bahia & 5 \\
Rio Grande do Sul & 2 \\
Santa Catarina & 1 \\
\hline Total & $\mathbf{8}$ \\
\hline
\end{tabular}


Tabela 3 Alunos participantes do grupo focado dos cursos de graduação presencial

\begin{tabular}{cc}
\hline Polo & Número de alunos \\
\hline Agronomia & 6 \\
Pedagogia & 8 \\
\hline Total & $\mathbf{1 4}$ \\
\hline
\end{tabular}

Ao final das sessões dos grupos focados, foram listados os fatores apontados pelos participantes e foi questionado se a lista estava completa ou se eles gostariam de incluir mais algum fator de engajamento. Complementarmente, buscando confirmação através de outras fontes de informações, realizou-se uma análise dos dados reunidos pela Comissão Própria de Avaliação (CPA) da Universidade Federal do Rio Grande do Sul. Essa análise utilizou o instrumento de avaliação respondidos pelos discentes, mais especificamente, a última questão na qual os alunos respondem livremente sobre sua percepção a respeito do seu curso. Foram utilizados os resultados observados em todos os cursos da modalidade a distância desde seu primeiro ano de curso.

$\mathrm{Na}$ última fase de coleta de dados investigou-se, ainda, o instrumento utilizado pelo INEP (Instituto Nacional de Estudos e Pesquisas Educacionais Anísio Teixeira) para subsidiar os atos de autorização de cursos de graduação.

\section{RESULTADOS DOS GRUPOS FOCADOS}

O primeiro grupo focado foi realizado com estudantes do curso de pedagogia a distância (PEAD). O curso de pedagogia teve seu início no segundo semestre de 2006. Os polos presenciais estavam localizados todos no Rio Grande do Sul nas cidades de Alvorada, Gravataí; Sapiranga; São Leopoldo e Três Cachoeiras. Esse curso foi sendo ofertado na forma de projeto especial, com dois períodos de ingresso ocorridos, respectivamente, no segundo semestre de 2006 e no primeiro semestre de 2007. Uma particularidade do curso é que todo o ingressante deveria, no momento do ingresso, pertencer à rede pública de ensino. Portanto, contempla alunos que já possuem alguma experiência na área do seu curso, visto este ser um projeto para atendimento de uma demanda específica, a de professores que permaneciam nos quadros das escolas públicas sem formação na área de atuação.

O segundo grupo focado foi realizado com os alunos do curso de música a distância (MUAD). O curso de música pertencia a um Programa de formação inicial voltado para professores que atuam nos sistemas públicos de ensino, nos anos/séries finais do Ensino Fundamental e/ou no Ensino Médio, e que não têm habilitação legal para o exercício da 
função (licenciatura). Assim, como observado no curso de pedagogia, os alunos também apresentavam alguma experiência no âmbito do curso. O curso de música constituiu-se por apenas uma turma, que ingressou no primeiro semestre de 2008. A diferença deste curso em relação ao anterior é sua maior dispersão em seus polos presenciais distribuídos por vários Estados do Brasil, sendo quatro no estado da Bahia, nas cidades de Cristópolis, Irecê, Salvador, São Félix; um no Espírito Santo, na cidade de Linhares; dois em Rondônia, nas cidades de Ariquemes e Porto Velho; um no Rio Grande do Sul, na cidade de Cachoeirinha; e três em Santa Catarina nas cidades de Canoinhas, Itaiópolis e São Bento do Sul. Todos os polos apresentam como sede a Universidade Federal do Rio Grande do Sul, localizada na cidade de Porto Alegre.

O terceiro grupo focado foi realizado junto ao curso de pedagogia presencial (PED) ofertado pela Universidade Federal do Rio Grande do Sul junto a Faculdade de Educação há 40 anos. Por fim, o quarto grupo focado reuniu estudantes do curso de Agronomia, também da UFRGS, ofertado pela Faculdade de Agronomia (AG).

A primeira questão discutida nos grupos focados foi: "Qual a percepção de vocês em relação ao curso de graduação que estão fazendo?". Pelas respostas obtidas pôde-se perceber a primeira diferença entre as duas modalidades de ensino. Ambos os cursos da modalidade a distância posicionaram-se afirmando sobre as dificuldades inerentes ao curso. Segundo alunos do PEAD, "é mais difícil do que muitos pensam, exige muita leitura e tempo, mas principalmente domínio das tecnologias”. Alunos do MUAD complementaram afirmando que “os tutores têm importante atribuição no polo, estão ali para dar suporte aos que necessitam... o fato de eu não precisar de auxílio não quer dizer que eles não têm serventia... é desta forma que percebo a estrutura do curso". Já os alunos do curso de PED revelaram sua preocupação em relação à empregabilidade que o curso pode proporcionar ao acadêmico, porém o curso apresenta "deficiências pois o aluno só vai ter contato com a prática do curso no segundo ano".

Acompanhando essa citação, muitos dos participantes do grupo indicaram que o contato com a prática é um fator de engajamento. O grupo focado da AG também afirmou que as atividades práticas desde o primeiro semestre do curso são fatores importantes para motivação dos alunos. Nos cursos a distância, foi consenso em ambos os grupos que a possibilidade de interação entre os colegas é um elemento importante para que os estudantes permaneçam. Também foi consenso que o papel dos docentes, sua motivação, seu feedback em relação às tarefas solicitadas e o fato de proporem atividades com complexidade 
condizente com a realidade do discente são outros fatores de engajamento. Os cursos à distância ainda destacaram, como elemento motivador, o papel do tutor e o seu conhecimento da tecnologia utilizada.

Quando questionados sobre "Quais as expectativas dos alunos em relação ao curso de graduação?" a empregabilidade foi fator predominante. Os alunos dos cursos a distância destacaram a possibilidade de melhorar a sua prática. Este fato possivelmente deve-se a característica da maioria dos estudantes já estarem inseridos no mercado de trabalho atuando na área do curso. Os estudantes também esperam conhecer novos profissionais, quer sejam docentes, quer sejam colegas. Os alunos do PED destacaram sua expectativa de que os docentes sejam capazes de articular teoria e prática. Os alunos esperam por melhorias em suas vidas de uma forma geral: social, econômica e intelectual.

Com a questão seguinte "Quais as atitudes dos alunos em relação aos seus cursos de graduação?" pôde-se detalhar dois momentos: antes do ingresso no curso superior e durante o período em que estão cursando. Nesta questão, tendo em vista que a principal característica que diferenciava os grupos dos cursos de graduação na modalidade presenciais e a distância é a experiência prática profissional, percebe-se que os discentes dos cursos a distância foram enfáticos ao afirmar, em ambos os cursos (PEAD E MUAD), a necessidade do aluno estar disposto a aceitar desafios e sua a capacidade de superação, tendo em vista que os cursos da modalidade a distância trazem consigo o desafio do conhecimento de ferramentas tecnológicas e a necessidade de superação, pois muitos alunos, até o momento antes do ingresso, não haviam tido contato com as tecnologias utilizadas no curso. Vale destacar uma diferença observada entre as modalidades dos cursos.

Os alunos do curso a distância observaram que mudaram suas atitudes relacionadas ao estudo após o ingresso no ensino superior. Eles se dizem mais comprometidos e disciplinados, principalmente no que diz respeito a organização de seu tempo. Já os alunos dos grupos focados dos cursos presenciais afirmam que o volume de "conteúdo a se estudar aumentou" (AG), porém, suas atitudes permanecem as mesmas. Particularmente, no grupo focado PED, foi destacado que a atitude do aluno depende em grande parcela do docente, visto que sua formação é em muito "inspirada por seus professores". Ainda, nos grupos presenciais foi destacado o fator da influência dos pais nas atitudes dos alunos frente ao curso de graduação (AG, PED).

A questão seguinte, “O engajamento do estudante pode gerar sucesso acadêmico? Qual o conceito de sucesso acadêmico na opinião de vocês?" revelou que as respostas do 
PEAD e MUAD estavam relacionadas com a possibilidade de "fazer a diferença na sua prática". O grupo AG destacou os resultados que o curso pode trazer para o seu "potencial de empregabilidade". Enquanto o PED destacou que o sucesso está ligado a possibilidade de melhoria de vida.

Por fim, a questão "Na opinião de vocês, quais os elementos que contribuem para gerar o engajamento dos alunos?” juntamente com outra questão buscando revelar mais fatores que porventura fossem esquecidos, "Vocês teriam mais alguma coisa a acrescentar em relação aos aspectos que geram engajamento dos alunos?" revelou aspectos que aqui podem ser divididos em três elementos essenciais: (i) pessoas, com destaque para o papel e atitudes dos docentes, acrescido do papel do tutor para os cursos a distância; (ii) tecnologia, contemplando a forma de acesso, a plataforma utilizada, os meios de comunicação e a velocidade da internet no polo, aspecto particularmente citado pelo PEAD E MUAD; e (iii) sistemas de ensino, envolvendo a quantidade e complexidade dos trabalhos e avaliações, quantidade e qualidade do material utilizado, e feedback do docente.

Por fim, é possível afirmar que o docente, ressaltado em todos os grupos focados, acompanhado pelo tutor, enfatizado nos grupos a distância, são fatores importante para o engajamento. Esta análise é reforçada pela coleta de dados realizada nos instrumentos de avaliação da CPA da Universidade. Os alunos ao responderem a avaliação do docente repetidamente destacam o papel do docente. Alguns momentos nomeando o docente ou o tutor, quer seja em forma de elogio, quer seja em forma de crítica. O docente, apesar da distância física, juntamente com o tutor presencial e a distância, aparece ressaltando seus conhecimentos em relação às ferramentas da tecnologia da informação e comunicação, em relação a sua didática ou a interação com os alunos.

O polo foi outro fator de engajamento apontado pelos grupos PEAD e MUAD, representado por seus equipamentos, salas de convivência e condições de acesso. Referente ainda ao polo, a biblioteca presencial revela-se como um elemento importante. As TICs, suas possibilidades e dificuldades, são também fatores reincidentes nos diversos instrumentos.

De modo geral, pode-se dizer que os elementos observados nos questionários da CPA foram representativos para este estudo uma vez que, o discurso dos grupos focados era por vezes repetido no instrumento escrito, quer seja na forma de reclamações, quer seja na forma de elogios. Portanto, esta fonte secundária de dados permitiu reforçar as análises e conclusões dos grupos focados. 
Por fim, foi consultado o instrumento do Instituto Nacional de Estudos e Pesquisas Anísio Teixeira, autarquia responsável pelo processo de condução da avaliação do ensino superior brasileiro. A consulta aos indicadores apresentados no instrumento permite complementar as dimensões assim como os fatores.

\section{FATORES DE ENGAJAMENTO NO ENSINO A DISTÂNCIA}

Os quadros a seguir apresentam as dimensões e os fatores de engajamento tendo em vista os resultados obtidos nas análises dos grupos focados, do questionário da CPA e do instrumento do Instituto Nacional de Estudos e Pesquisas Anísio Teixeira.

Quadro 3 Dimensão 1: Formação acadêmica anterior e aptidão

\begin{tabular}{|c|c|}
\hline DIMENSÕES & FATORES DE ENGAJAMENTO \\
\hline \multirow{4}{*}{$\begin{array}{c}\text { Formação } \\
\text { acadêmica }\end{array}$} & Preparo para o mundo universitário \\
\cline { 2 - 2 } anterior e aptidão & Experiências práticas antes da Universidade \\
\cline { 2 - 2 } & Conhecimento do curso antes de ingressar no mesmo \\
\cline { 2 - 2 } & Trabalhos realizados na área antes do ingresso no curso \\
\cline { 2 - 2 } & Grau de aptidão e maturidade para o curso \\
\cline { 2 - 2 } & Formação dos pais \\
\hline
\end{tabular}

A dimensão Formação acadêmica, apresentada no Quadro 3, foi definida agrupando as opiniões emitidas pelos participantes dos grupos focados, a exceção do fator Formação dos pais. O preparo para o mundo universitário diz respeito a fala de alguns participantes que afirmavam não ter "noção do que é estar no ensino superior" portanto, os alunos chegavam despreparados para a quantidade de trabalho e a necessidade de autonomia para o estudo. Esse fator acabava por determinar a desistência de alguns colegas, conforme foi mencionado. Semelhante ao fator preparo para o mundo universitário, o fator experiências práticas antes da Universidade foi abordado pelos participantes que afirmaram que as experiências anteriores auxiliam ao aluno "acertar seu curso", conhecendo melhor o que "ia enfrentar".

Em relação ao fator conhecimento do curso antes de ingressar no mesmo, diz respeito à falta de informação que muitas vezes o aluno se depara ao iniciar o seu curso superior. Segundo os respondentes, o desconhecimento leva a uma frustração e muitas vezes a desistência. Trabalhos realizados na área antes do ingresso no curso foi mencionado como sendo a experiência prévia, um item importante até mesmo na escolha adequada do curso.

O grau de aptidão e maturidade para o curso surge com a ideia de que muitas vezes o aluno desconhece suas próprias competências antes de ingressar, portanto, se não tiver 
aptidão ou maturidade para uma determinada área, acaba muitas vezes frustrando-se não somente com o curso, mas, também com o próprio ensino superior.

A Formação dos pais é apontada no instrumento socioeconômico utilizado para cálculo do conceito parcial de curso (CPC) realizado pelo Ministério da Educação, atribuindo um conceito aos cursos de graduação. Ela pode contribuir para sustentar (ou não) a permanência do estudante em seu curso.

Quadro 4 Dimensão 2: Características individuais dos alunos

\begin{tabular}{|c|c|}
\hline \multirow{3}{*}{$\begin{array}{c}\text { Características } \\
\text { individuais do } \\
\text { aluno }\end{array}$} & Curiosidade e interesse natural pelos assuntos do curso \\
\cline { 2 - 2 } & Disciplina e organização do tempo \\
\cline { 2 - 2 } & Vivência prática e capacidade de visualizar a aplicação dos conteúdos \\
\cline { 2 - 2 } & Capacidade de superação e aceitar desafios \\
\hline
\end{tabular}

Os participantes dos grupos afirmam que há algumas características individuais que facilitam o engajamento do aluno em cursos a distância. Entre essas características, foram destacadas: independência individual e pró-atividade; curiosidade e interesse natural pelos assuntos do curso; disciplina e organização do tempo; vivência prática e capacidade de visualizar a aplicação dos conteúdos, capacidade de superação e aceitar desafios. Essas características, resumidas no Quadro 4, estão associadas ao fato do aluno de cursos a distância não ter um acompanhamento presencial do professor, exigindo que ele, de forma independente, tome decisões, organize seu estudo, aceite desafios e busque superá-los.

Quadro 5 Dimensão 3: Resultados Esperados

\begin{tabular}{|c|c|}
\hline \multirow{3}{*}{$\begin{array}{c}\text { Expectativas } \\
\text { referentes a }\end{array}$} & Possibilidade de vivenciar a prática \\
\cline { 2 - 2 } conhecimento e & Possibilidade de articulação dos conteúdos de sala de aula com a \\
empregabilidade & realidade \\
\cline { 2 - 2 } & Possibilidade de qualificar seu trabalho e empregabilidade \\
\cline { 2 - 2 } & Possibilidade de Melhoria de currículo e empregabilidade \\
\cline { 2 - 2 } & Possibilidade de formação de redes de relacionamento profissional \\
\hline
\end{tabular}

Em todos os grupos focados realizados a questão das Expectativas referentes a conhecimento e empregabilidade, traduzidas no Quadro 5, foi abordada espontaneamente. As perspectivas de "melhorar de vida", através de conhecimento e emprego, na percepção dos participantes, gera maior engajamento.

A possibilidade de vivenciar a prática é um fator mencionado como de extrema importância. Os participantes dos grupos focados afirmaram que o curso deveria oferecer disciplinas práticas desde o primeiro semestre de forma que fosse possibilitado ao aluno 
“conhecer seu campo de atuação" logo que ingressa na faculdade. Seguindo esta mesma linha, foi incluído o fator articulação dos conteúdos de sala de aula com a realidade, uma vez que os alunos afirmam que sente a necessidade de conhecer a "utilidade" daquilo que estão aprendendo.

Os fatores melhoria de currículo, possibilidade de qualificar o seu trabalho, possibilidade de empregabilidade e possibilidade de formação de redes de relacionamento representam questões básicas para a empregabilidade. Os respondentes afirmam desejarem ter novas perspectivas ao terminarem seus cursos de graduação.

Quadro 6 Dimensão 4: Participação em atividades acadêmica

\begin{tabular}{|c|c|}
\hline \multirow{4}{*}{$\begin{array}{c}* \\
\text { Participação em } \\
\text { atividades } \\
\text { acadêmicas }\end{array}$} & Participação em trabalhos em grupo \\
\cline { 2 - 2 } & Anterações com on coline à biblioteca \\
\cline { 2 - 2 } & Interações com os colegas em atividades acadêmicas \\
\cline { 2 - 2 } & Tempo gasto elaborando trabalhos sociais \\
\cline { 2 - 2 } & Temdividuais e estudando \\
\hline
\end{tabular}

A dimensão participação em atividades acadêmicas, resumida no Quadro 6, está contemplada, uma vez que os alunos afirmaram que sentiam a necessidade de "pertencer" ao ensino superior. Por isso, sempre que podiam, estavam presentes no polo de apoio presencial. Os participantes dos grupos focados ressaltaram a importância e a necessidade de ter interações com os colegas em atividades sociais e/ou acadêmicas, assim como a participação em trabalhos em grupo.

Os alunos lembraram que, no início do curso, fizeram o controle do tempo por meio do uso de um diário, no qual relatavam todas as atividades executadas ao longo de seu dia e no fim buscavam verificar quanto do tempo era despendido estudando e elaborando trabalhos individuais. Esse fator foi importante para que eles tomassem consciência da necessidade de estudar e se engajassem.

$\mathrm{O}$ acesso online à biblioteca é um requisito legal, visto como item de qualidade.

Quadro 7 Dimensão 5: Condições do polo presencial

\begin{tabular}{|c|c|}
\hline \multirow{4}{*}{$\begin{array}{c}\text { Condição } \\
\text { do polo }\end{array}$} & Facilidade de acesso físico ao polo(localização) \\
\cline { 2 - 2 } presencial & Disponibilidade de Horários de funcionamento do polo \\
\cline { 2 - 2 } & Facilidade de acesso à biblioteca presencial \\
\cline { 2 - 2 } & Disponibilidade de Espaço de convivência presencial \\
\cline { 2 - 2 } & Flexibilidade nas Participaçóes presenciais \\
\hline
\end{tabular}


A Dimensão 5 (ver Quadro 7) foi construída baseando-se fundamentalmente nas exigências legais expostas nos instrumentos de autorização de polo, assim como nos referenciais de qualidade do EAD publicados pelo Ministério da Educação do Brasil. Para que um polo possa existir é necessário que ele tenha uma biblioteca física, na qual o estudante tenha acesso em horários amplos. Também é necessário um espaço de convivência, assim como laboratórios de informática ou laboratórios especializados, no caso de cursos nos quais exista a exigência legal em suas Diretrizes Curriculares Nacionais.

As participações presenciais também são exigências legais, conforme decreto $5622 / 2005$, estabelecendo que o estudante deverá realizar as avaliações de forma presencial, assim como defesas de trabalhos de conclusão de curso e estágios obrigatórios, quando previstos na legislação pertinente e atividades relacionadas a laboratórios de ensino, quando for o caso de acordo com as Diretrizes Curriculares Nacionais de curso.

Quadro 8 Dimensão 6: Sistemas de ensino

\begin{tabular}{|c|c|}
\hline \multirow{4}{*}{$\begin{array}{c}\text { Sistemas de } \\
\text { Ensino }\end{array}$} & Quarga horária da disciplina \\
\cline { 2 - 2 } & Quade dos materiais utilizados em aula \\
\cline { 2 - 2 } & Dinâmicas de ensino \\
\cline { 2 - 2 } & Quantidade de disciplinas que despertam o interesse pessoal \\
\cline { 2 - 2 } & Sistemas de avaliação usados nas disciplinas \\
\cline { 2 - 2 } & Feedback da secretaria \\
\cline { 2 - 2 } & Integração das disciplinas \\
\hline
\end{tabular}

Os fatores enumerados no Quadro 8, compreendendo a dimensão sistemas de ensino, são baseados tanto em aspectos legais como na percepção dos participantes dos grupos focados.

O fator carga horária da disciplina pode ser visto tanto no que tange a questão legal de carga horária mínima do curso, quanto na afirmação dos respondentes que existem disciplinas com muita carga horária para pouco conteúdo, assim como disciplinas com pouca carga horária para um excesso de conteúdo.

As dinâmicas de ensino são apontadas como uma necessidade do aluno buscar formas diferenciadas de abordar os conteúdos das disciplinas. Outro fator, diz respeito à quantidade de disciplinas que despertam o interesse pessoal do aluno, quanto mais essas existirem, maior será o engajamento do estudante. De forma similar, aparece a necessidade de integração das disciplinas de modo que o estudante possa entender e "valorizar" o que está sendo trabalhado. 
O equilíbrio entre os sistemas de avaliação usados nas disciplinas e os seus conteúdos, assim como a clareza nas explicações acerca da avaliação,também foi indicado pelos respondentes.

Feedback da secretaria foi outro ponto abordado pelos respondentes como importante para que o aluno possa se sentir engajado aos estudos. O feedback neste caso está associado tanto à qualidade, quanto ao tempo entre a entrega de determinada solicitação e a resposta dos diversos setores da Instituição de ensino, assim como as respostas relativas a questionamentos realizados ao longo do curso.

A qualidade dos materiais é um fator avaliado pelo instrumento do INEP quando ocorre o credenciamento de polo, assim como um referencial de qualidade relativo à legislação pertinente.

Quadro 9 Dimensão 7: Suporte acadêmico

\begin{tabular}{|c|c|}
\hline \multirow{4}{*}{ Suporte } & Capacidade do Suporte online na resolução de problemas \\
\cline { 2 - 2 } Acadêmico & Capacidade do Suporte presencial na resolução de problemas \\
\cline { 2 - 2 } & Disponibilidade de treinamento para utilizar as plataformas \\
\cline { 2 - 2 } & Dacilidade de uso das plataformas \\
\cline { 2 - 2 } & Disponibilidade de computadores no polo \\
\cline { 2 - 2 } & Disponibilidade de internet rápida \\
\hline
\end{tabular}

O Suporte acadêmico, conforme apresentado no Quadro 9, é uma dimensão importante para o engajamento do estudante. Uma vez que os princípios da educação a distância dizem respeito a tempo e espaço, o aluno deve ter condições de acesso à plataforma em seu próprio tempo, em condições adequadas de uso e acesso. Portanto, o suporte online ou presencial deve existir e ser de fácil acesso. Quando o sistema utilizado pela instituição apresenta problemas de conexão, o aluno fica "desmotivado", conforme afirmam os respondentes.

Outro fator que foi ressaltado é o treinamento para utilizar as plataformas. Se o aluno inicia o curso com problemas no uso da ferramenta, o mesmo percebe maiores dificuldades no próprio curso. No mesmo sentido, é apontado o fator facilidade de uso das plataformas e rapidez da internet. Alguns alunos afirmaram que desenvolveram sua capacidade de uso da tecnologia da informação e comunicação, o que não tinham antes do ingresso no curso. Por fim, o fator qualidade de equipamentos é representado como um requisito legal.

Tendo em vista os papéis assumidos por docentes e tutores no EAD são identificados os mesmo fatores para ambos os atores, conforme é demonstrado nos Quadros 10 e 11. 
Quadro 10 Dimensão 8: Docentes

\begin{tabular}{|l|c|}
\hline \multirow{4}{*}{ Docentes } & Interesse dos docentes pelo ensino \\
\cline { 2 - 2 } & Conhecimento teórico do docente \\
\cline { 2 - 2 } & Conhecimento prático do docente \\
\cline { 2 - 2 } & Conhecimento das tecnologias utilizadas no curso por parte do docente \\
\cline { 2 - 2 } & Feedback do docente \\
\hline
\end{tabular}

Quadro 11 Dimensão 9: Tutores

\begin{tabular}{|c|c|}
\hline \multirow{4}{*}{ Tutores } & Interesse dos tutores pelo ensino \\
\cline { 2 - 2 } & Conhecimento teórico do tutor \\
\cline { 2 - 2 } & Conhecimento prático do tutor \\
\cline { 2 - 2 } & Conhecimento das tecnologias utilizadas no curso por parte do tutor \\
\cline { 2 - 2 } & Feedback do tutor \\
\hline
\end{tabular}

O quadro 10 traduz a dimensão associada aos docentes, apresentando fatores que dizem respeito ao seu interesse pelo ensino dos alunos, ao seu conhecimento teórico e prático, assim como o conhecimento das tecnologias utilizadas no curso. Por fim, e não menos importante, o feedback continuado e rápido dos docentes aparece como fator fundamental

No modelo de EAD brasileiro, em algumas instituições, surge outro mediador do processo de ensino-aprendizagem, o tutor. Os instrumentos de autorização de curso e credenciamento institucional dedicam indicadores para avaliar sua experiência, formação, número de tutores por alunos e capacitação em EAD. O tutor passa a ter também uma forte interação com os alunos. No transcorrer dos grupos focados ele aparece em destaque, conforme a lista de fatores apresentadas no Quadro 11.

A interação com o tutor é frequente, conforme afirmam os entrevistados. Os participantes dos grupos focados afirmam que interesse tanto do tutor como do docente pelo ensino é um fator chave para que o próprio aluno sinta-se engajado. O conhecimento teórico e prático assim como o conhecimento das tecnologias utilizadas no curso por parte do tutor faz com que o aluno o procure com mais frequência, tornando-o mais engajado. Por fim, o feedback do tutor, rápido, faz com que o aluno possa dar sequência a seus estudos de forma mais imediata, não causando interrupções, que acabam diminuindo o engajamento. 
Quadro 12 Dimensão 10: Materiais educacionais

\begin{tabular}{|c|c|}
\hline \multirow{4}{*}{$\begin{array}{c}\text { Materiais } \\
\text { Educacionais }\end{array}$} & Tipo de material \\
\hline & Volume e conteúdo do material \\
\hline & $\begin{array}{c}\text { Abordagem Interdisciplinar e Contextualizada dos Conteúdos dos } \\
\text { materiais }\end{array}$ \\
\hline & Guia de Conteúdos (módulos, unidades, etc.) para o Estudante \\
\hline
\end{tabular}

A dimensão materiais educacionais, traduzida no Quadro 12, foi construída tomando por base os referenciais de qualidade para cursos na modalidade a distância divulgados pelo Ministério da Educação. Também são consideradas algumas afirmações dos participantes dos grupos focados, quando abordam o volume e o conteúdo do material utilizado, assim como a necessidade de integração entre os materiais gerando uma abordagem interdisciplinar e contextualizada dos conteúdos utilizados ao longo do curso.

Quadro 13 Dimensão 11: Ambiente Virtual de Aprendizagem

\begin{tabular}{|c|c|}
\hline \multirow{4}{*}{$\begin{array}{c}\text { Ambiente Virtual } \\
\text { de Aprendizagem }\end{array}$} & Fesolução rápidade de problemas no AVA \\
\cline { 2 - 2 } & Tempo do processamento do AVA \\
\cline { 2 - 2 } & Possibilidades de trabalho colaborativo no AVA \\
\cline { 2 - 2 } & Disponibilidade de ferramentas e serviços no AVA \\
\cline { 2 - 2 } & $\begin{array}{c}\text { Compatibilidade do AVA com os recursos disponíveis na casa dos } \\
\text { alunos }\end{array}$ \\
\hline
\end{tabular}

Ao projetar um curso na modalidade a distância com apoio de tecnologias da informação e comunicação, a instituição de ensino deve fazer a escolha por um ambiente virtual de aprendizagem (AVA). O Quadro 13 resume os fatores envolvidos. Esse ambiente deve ser de fácil uso. Os participantes dos grupos focados apontaram que o primeiro desafio ao ingressar em um curso na modalidade a distância diz respeito ao próprio uso da tecnologia. Quanto maior a complexidade do uso, menor o engajamento dos alunos. O ambiente deve estar disponível, evitando interrupções que impeçam o acesso no momento que o aluno necessita. Os entrevistados apontaram ainda a questão das próprias dificuldades tecnológicas em suas casas para o acesso do AVA, o que gera desmotivação.

\section{CONSIDERAÇÕES FINAIS}

A inclusão dos fatores de engajamento do estudante contribui para gerar informações relevantes e compreender a complexidade do sistema. Em países que utilizam o engajamento como uma medida de avaliação da qualidade, ele é vislumbrado como forma de demonstrar a eficiência do sistema. Os modelos de engajamento dos estudantes apresentados na literatura 
internacional foram desenvolvidos para medir em que extensão os estudantes estão engajados em atividades com propósitos educacionais que contribuem para seu aprendizado (KUH; HU, 2001). Há mais de duas décadas, o engajamento do estudante vem sendo destacado como um importante elemento para o aprendizado e sucesso acadêmico (ASTIN, 1993; PASCARELLA; TERENZINI, 2001). Portanto, não representa somente uma imagem da Instituição de ensino, mas uma forma de avaliação da eficiência e eficácia do processo de ensino e aprendizagem.

Particularmente, o EAD vem se expandindo no Brasil nos últimos anos, segundo dados apresentados pelo INEP. Conforme aponta Alonso (2010), os modelos de avaliação utilizados para a modalidade de EAD ainda estão baseados em requisitos desenvolvidos para cursos presenciais. Neste sentido, surge a necessidade de investigar indicadores que sustentem a organização dos sistemas de EAD (ALONSO, 2010).

O presente artigo objetivou identificar e organizar em dimensões os fatores que geram engajamento acadêmico no EAD, mediante os dados obtidos junto a universitários em diferentes períodos de seus cursos e diversas áreas do conhecimento. Em primeiro lugar, com base nos resultados, foi possível identificar onze dimensões que são detalhadas em 60 fatores de engajamento.

O principal fator de destaque, pouco discutido na literatura, diz respeito ao papel do docente e do tutor no engajamento. Em todas as questões apresentadas nos grupos focados, bem como nos instrumentos utilizados pela CPA, docentes e tutores eram destacados em suas funções. De alguma forma, pode-se afirmar que o próprio engajamento do docente-tutor é um fator que pode gerar engajamento do estudante.

As tecnologias da informação e comunicação aparecem também como fatores que podem facilitar ou dificultar a vida acadêmica e o engajamento dos estudantes na modalidade a distância. As dificuldades podem ser relacionadas à infraestrutura do polo, à complexidade das plataformas utilizadas ou aos serviços de suporte para o uso da tecnologia.

Os materiais educacionais não foram fatores destacados pelos estudantes nos grupos focados, mas acredita-se que esta seja uma dimensão importante a ser avaliada, uma vez que essa dimensão é mencionadanos referenciais de qualidade dos cursos na modalidade a distância. Essa dimensão é representada por indicadores que levam a Instituição de Ensino Superior a elaborar e implantar uma série de serviços para atendimento de seus alunos.

Enquanto sugestão para pesquisas futuras sugere-se a realização de estudos que permitam validar os fatores e as dimensões identificadas ao longo deste artigo. 


\section{REFERÊNCIAS}

ALONSO, Kátia Morosov. A expansão do ensino superior no Brasil e a EaD: dinâmicas e lugares. Educação \& Sociedade, v. 31, n. 113, p. 1319-1335, 2010.

ASTIN, Alexander W. Involvement: The cornerstone of excellence. Change. v. 17, n. 4, p. 35-39, 1993.

ASTIN, Alexander W. Student involvement: A developmental theory for higher education. Journal of College Student Development. v. 25, p. 297-308, 1984.

CHEN, Pu-Shih Daniel; GONYEA, Robert; KUH, George D. Learning at a distance: Engaged or not. Innovate: Journal of Online Education, v. 4, n. 3, p. 208, 2008.

CHICKERING, Arthur; EHRMANN, Stephen. Implementing the seven principles:

Technology as lever. Disponível em: http://www.tltgroup.org/programs/seven.html Acesso em: 20 de fevereiro de 2014

COATES, Hamish. A Model of Online and General Campus-Based Student Engagement. Assessment and Evaluation in Higher Education. v. 32, n.2, p. 121-141, 2007.

CRUCE, Ty et al. Impacts of Good Practices on Cognitive Development, Learning Orientations, and Graduate Degree Plans during the First Year of College. Journal of College Student Development. v.47, n. 4, pp. 365-383, 2006.

DIXSON, Marcia D. Creating effective student engagement in online courses: What do students find engaging? Journal of the Scholarship of Teaching and Learning, v. 10, n. 2, p. 1-13, 2012.

DUDERSTADT, James; ATKINS, Daniel; HOUWELING, Douglas Van. Higher Education Faces the Digital Age: Technology Issues and Strategies for American Colleges and Universities, Washington, DC.: Greenwood Press, 2002

EWELL, Peter; JONES, Denis. Indicators of "Good Practice" in Undergraduate Education: A Handbook for Development and Implementation, 1996. Disponível em: http://files.eric.ed.gov/fulltext/ED403828.pdf. Acesso em 15 fev. 2014

FREDRICKS, Jennifer A.; BLUMENFELD, Phyllis C.; PARIS, Alison H. . School engagement: Potential of the concept, state of the evidence. Review of educational research, v. 74, n. 1, p. 59-109, 2004.

HU, Shouping; WOLNIAK, Gregory C. Initial evidence on the influence of college student engagement on early career earnings. Research in Higher Education, v. 51, n. 8, p. 750-766, 2010 .

KUH, George D. What Student Affairs Professionals Need to Know about Student Engagement. Journal of College Student Development. v. 50, n. 6, pp. 683-706, 2009.

KUH, George D. et al. Unmasking the Effects of Student Engagement on First-Year College Grades and Persistence. Journal of Higher Education. v. 79, n.5, pp. 540-563, 2008. 
KUH, George D.; HU, Shouping. The Effects of Student Faculty Interaction in the 1990s. Review of Higher Education. v. 24, n.3, pp. 309-332, 2001.

LAIRD, Thomas F. Nelson; KUH, George D. Student experiences with information technology and their relationship to other aspects of student engagement. Research in Higher Education, v. 46, n. 2, p. 211-233, 2005.

LAPADULA, Maria A comprehensive look at online student support services for distance learners. The American Journal of Distance Education, v. 17, n. 2, 119-128, 2003.

MAEROFF, Gene I. A classroom of one: How online learning is changing our schools and colleges. London: Palgrave Macmillan, 2003.

MAIA, Marta de Campos.; MEIRELLES, Fernando de Souza. Information Technology applied to Distance Education in Business Administration courses in Brazil. BUSINESS ASSOCIATION OF LATIN AMERICA 2003. Disponível em:

http://www.researchgate.net/profile/Marta Maia/ publication/266080455 INFORMATION TECHNOLOGY APPLIED TO DISTANCE E DUCATION IN BUSINESS ADMINISTRATION COURSES IN BRAZIL/links/5424b5 420cf238c6ea73b51f.pdf. Acesso em 15 fev. 2014.

MOORE, Michael G. Three types of interaction. The American Journal of Distance Education, v. 3, n. 2, 1989.

PACE, C. Robert.. The Undergraduates: A Report of Their Activities and Progress in College in the 1980's. 1990. Disponível em: http://files.eric.ed.gov/fulltext/ED375701.pdf. Acesso em 20 fev. 2015.

PALLOFF, Rena M.; PRATT, Keith. Working with the Virtual Student. 2001. Disponível em: http://ahea.org/files/pro1999palloff.pdf. Acesso em 10 fev. 2014

PASCARELLA, Ernest T. Using student self-reported gains to estimate college impact: A cautionary tale. Journal of college student development, 2001.

PASCARELLA, Ernest T.; TERENZINI, Patrick T. How College Affects Students: A Third Decade of Research (Vol. 2). San Francisco: Jossey-Bass, 2005

PIKE, Gary R.; KUH, George D. A Typology of Student Engagement for American Colleges and Universities. Research in Higher Education. v. 46, n. 2, p. 185-209, 2005.

RIBEIRO, José Luis Duarte; NODARI, Christine T. Tratamento de dados qualitativos: técnicas e aplicações. Porto Alegre: FEENG, v. 130, 2001.

ROBINSON, Chin Choo; HULLINGER, Hallett. New Benchmarks in Higher Education: Student Engagement in Online Learning. Journal of Education for Business. v. 84. n. 2 pp: 101-109, 2008. 
ROVAI, Alfred P.. A practical framework for evaluating online distance education programs. Intenet and Higher Education. v.6, pp 109-124, 2003.

SHERRY, Lorraine. Issues in distance learning. International journal of educational telecommunications. v. 1, n. 4, p. 337-365, 1995.

SUN, Jerry Chih-Yuan; RUEDA, Robert. Situational interest, computer self-efficacy and selfregulation: Their impact on student engagement in distance education. British Journal of Educational Technology, v. 43, n. 2, p. 191-204, 2012.

THURMOND, Veronica A.; WAMBACH, Karen. Understanding interactions in distance education: A review of the literature. International Journal of Instructional Technology and Distance Learning, v. 1, n. 1, 2004.

TINTO, Vincent. Leaving College: Rethinking the Causes and Cures of Student Attrition. 2nd ed. Chicago, IL: University of Chicago Press, 1993.

WESTPLTAL, Marcia Faria; BÓGUS, Claudia Maria; FARIA, Mara de Melo. Grupos focais: experiências precursoras em programas educativos em saúde no Brasil. Boletín de Oficina Sanitaria Panamerican, 1996.

ZHAO, Chun-Mei; KUH, George D. Adding Value: Learning Communities and Student Engagement. Research in Higher Education, v. 45, n. 2, March, 2004. 